\title{
Desregulación y equidad: el proceso de reconversión de Obras Sociales en Argentina
}

\author{
Deregulation and equity: the $\mathrm{O}$ bras Sociales \\ reconversion process in Argentina
}

Liliana Findling 1

María Arruñada 1

Ezequiel Klimovsky 1

\footnotetext{
1 Instituto Gino Germani, Facultad de Ciencias Sociales, Universidad de Buenos Aires. J. E. Uriburu 950, 6to piso, Buenos Aires 1114, Argentina.
}

Abstract The health care services managed by tradeunions and known as "Obras Sociales" form the groundwork for Argentina's Social Security and Health system. However, far from taking an equitable approach, these institutions highlight the country's prevailing income disparities, which in turn lead to maj or differences in access to care. The main focus of this study was the reformulation of social security health policies within the framework of deregulation from 1998 to 2000, analyzing the effects on availability of health care services from an equity perspective. The methodology used two related analytical levels: (1) a macro level viewing the process from the various players' strategies and (2) a mi cro level featuring the changes within a well-known trade union social security organization during its reconversi on process, emphasizing its institutional scope and the opinions of its membership. The results thus pointed to the sl ow implementation of reforms initiated by the public sector, hindered by constant negotiations among the main corporate actors seeking to serve their particular interests, al ong with increased inequity and fragmentation due to the limited opening of free choice by members.

Key words Equity; Health Services; Health Services Accessibility; Health Policy

Resumen Las Obras Sociales constituyen la base de la organización de la Seguridad Social Mé dica en Argentina. Lejos de tener un carácter equitativo, estas insti tuci ones reproducen las desi gualdades de ingresos vigentes en la actividad económica, provocando profundas disparidades en el nivel delos servicios médicos. El objetivo general del proyecto se centró en estudiar el proceso de reformulación dela política dela Seguridad Social Médica en el marco de sus intentos desregulatori os durante el período 1998-2000, analizando los efectos sobre la equidad en el acceso a los servi cios de salud. La metodología abordó el estudio desde dos niveles de análisis articulados entre sí: (1) un nivel macro, que tuvo en cuenta la evolución del proceso desde las estrategias de los actores invol ucrados y, (2) un nivel micro, caracterizando los cambios que se producen al interior de una reconocida obra social sindical durante su proceso de reconversión, teniendo en cuenta la órbita institucional y la visión de los afiliados. Los resultados visual izan una lenta implementación de las reformas propuestas desde el Estado, que se ve entorpeci da por continuas negociaciones entre los princi pales actores corporativos, que imponen sus intereses, y una creciente inequidad y mayor fragmentación por la apertura de la libre elección entreafiliados. Palabras clave Equidad; Servicios de Salud; Accesibilidad a los Servicios de Salud; Política de Salud 


\section{Introducción}

Las políticas de ajuste que se han aplicado en el país, y especialmente las exigencias de una economía globalizada, han reestructurado el débil Estado de Bienestar alcanzado en décadas anteriores. El Partido Justicialista, a cargo del Dr. Menem, que gobernó el país desde 1989 hasta 1999, trasladó acríticamente los presupuestos básicos de las propuestas neoliberales centradas en la restitución del mercado como rector de la vida social y en la redefinición de los ámbitos de intervención estatal. A fines de la década de los 90, los indicadores macro-económicos de Argentina muestran una creciente inestabilidad como producto de la apertura económica, de la política de privatizaciones y de la desregulación estatal y financiera, en un contexto signado por el incremento de la deuda externa, desiguales patrones de crecimiento, regresiva distribución del ingreso y una mayor exclusión social asociada con el desempleo y com la precarización laboral. Más quizás que en otros campos del área social, las políticas de salud implementadas a lo largo del tiempo en el país dieron lugar a instituciones cuyas características más salientes son la fragmentación, la desigualdad y la diferenciación, con agudas brechas de los indicadores sanitarios regionales. El sistema de salud está conformado por el sector público, el privado y el de obras sociales. Todos comparten el financiamiento, la producción y la provisión de los servicios, con un gasto total en salud estimado para 1997 del 8,2\% del Producto Bruto Interno (González-García \& Tobar, 1997). Se detalla la cobertura de la población según los diferentes sectores (Tabla 1).

El financiamiento se origina en 3 fuentes: los impuestos (nacionales, provinciales y municipales), las contribuciones a la Seguridad Social y la compra directa de seguros y copagos, en el caso del sector privado. El sector público (que insume el $23 \%$ del total del gasto en salud) provee directamente servicios a través de la red de hospitales públicos que son, en su mayoría, provinciales y municipales, como producto de una progresiva descentralización del gasto a nivel nacional. El sector privado brinda fundamentalmente servicios a las obras sociales sin infraestructura propia, cubre a la población no asegurada de medianos y altos ingresos a través de empresas de medicina pre-paga e insume el $40 \%$ del gasto total del sector $(30 \%$ de desembolso directo y $10 \%$ para seguros de salud privados). Las Obras Sociales insumen el $37 \%$ del gasto en salud. Una parte es financiada por partidas del presupuesto general, pero la mayor proporción se cubre con fondos que se ori- ginan en impuestos al trabajo: son aportes y contribuciones sobre el salario de los trabajadores en relación de dependencia (5\% por parte del empleador y $3 \%$ del empleado). Su cobertura alcanza a alrededor del $50 \%$ de la población del país (incluyendo a familiares), cifra que asciende a 17 millones de habitantes en 1995 (González-García \& Tobar, 1997). Esas entidades han sentado las bases de un sistema de seguridad social médico solidario en cada uno de los gremios: cada trabajador realiza aportes en función de su nivel salarial y obtiene prestaciones de salud - no necesariamente proporcionales - relacionadas con el monto de recursos gl obales que percibe cada entidad. Los recursos, a su vez, dependerán del nivel salarial medio de la rama de actividad correspondiente (Cetrángolo \& Devoto, 1998).

El sector se regula por el Fondo Solidario de Redistribución (FSR), que es financiado en forma conjunta por un porcentaje de las contribuciones de empleadores y empleados a su Obra Social. Los montos del FSR deberían ser reasignados, a través de un mecanismo automático de subsidios, para aquellas entidades que perciben bajos montos de ingreso promedio por beneficiario y para el financiamiento de planes especiales de salud.

Está constituido por 280 entidades de diversa naturaleza, pero nuestro estudio se centra en las obras sociales nacionales de origen sindical (209 instituciones) a cargo de los gremios.

Los profundos cambios operados en el mercado de trabajo desde mediados de los años 70, expresados en un descenso de la tasa de asalarización y el crecimiento del mercado informal, redujeron la base de los mecanismos financieros que nutren a las obras sociales y provocaron fuertes desequilibrios económicos, haciendo más visibles los rasgos de heterogeneidad e inequidad en las prestaciones. La interdependencia que caracteriza a los mercados de salud y la presencia de actores corporativos con fuertes intereses en el sector (pugna distributiva entre sindicatos, Estado y grandes grupos de prestadores) produjeron, a fines de la década del 80, fuertes distorsiones financieras, generalizándose el pago de coseguros para los usuarios. La expulsión de demanda a los hospitales públicos en búsqueda de atención gratuita por parte de los afiliados de menores recursos significó de hecho una mayor estratificación de la demanda.

La crisis financiera no sólo desplegó entre los prestadores mecanismos perversos, sino también se profundizaron prácticas clientelísticas y una inadecuada administración por parte de la dirigencia de las obras sociales. Esta 
debilidad, sumada a los crecientes manejos discrecionales del FSR, ha contribuido, sin duda, a una deslegitimación de estas entidades.

El argumento central de la reforma de Obras Sociales, que no se plantea explícitamente disminuir la inequidad al interior del sistema, intenta aumentar la eficiencia y la eficacia de su funcionamiento y se centra en desregular su dinámica, apuntando a eliminar el carácter cautivo de la población beneficiaria (Katz et al., 1993). Desde el Ministerio de Salud se sostenía que la libertad de elección aumentaría la competencia entre obras sociales y prestadores, lo que haría más eficiente el sistema. No será el Estado sino los propios individuos, en el uso pleno de sus derechos, los encargados de castigar prestadores y obras sociales ineficientes, incentivando un proceso de selección natural que hará más racional el uso de los servicios.

Los principales ejes de la desregulación de obras sociales, decretada a partir de 1993, pero implementada en 1997, se han centrado en: (a) imponer la libre elección de afiliados entre obras sociales nacionales; (b) crear un Programa Médico Obligatorio (canasta básica de prestaciones de salud) para los afiliados de Obras Sociales y de empresas de medicina pre-paga; (c) introducir modificaciones en el FSR para compensar los desniveles de ingreso entre las entidades; y (d) crear un Fondo de Reconversión para Obras Sociales (FROS) financiado por el Banco Mundial.

El objetivo general del proyecto se centró en estudiar el proceso de reforma de las obras sociales, durante el período 1998-2000, teniendo en cuenta la visión de los actores involucrados, analizando los efectos que produce desde la perspectiva de equidad en el acceso a los servicios de salud, y relacionando el nivel de formulación y discusión de dicha política con el de su implementación, a nivel micro, en una obra social en particular. Los objetivos específicos apuntaron a: (1) analizar los principales ejes de la reforma; (2) explorar las tomas de posición de los diferentes actores involucrados y, (3) describir - a modo de estudio de caso - los cambios institucionales acaecidos en la obra social sindical de la Unión Obrera Metalúrgica (UOM), evaluando la calidad de la atención de sus servicios desde la visión de sus afiliados, a fin de detectar situaciones de inequidad en el acceso a la salud.

La metodología abordó un diseño descriptivo, cuali-cuantitativo y diacrónico en base al análisis de fuentes secundarias (revisión de estadísticas, análisis documental y principales periódicos) y fuentes primarias (entrevistas en profundidad a actores - funcionarios estatales del área de salud, dirigentes de sindicatos y
Tabla 1

Distribución de la población según cobertura de salud, 1997.

\begin{tabular}{lr}
\hline Tipo de cobertura & Población (\%) \\
\hline Obra Social solamente & 47 \\
Mutual y/o pre-paga privada & 4 \\
Obra Social y pre-paga & 3 \\
Hospital público & 46 \\
Total & 100 (34,6 millones)
\end{tabular}

Fuente: González-García \& Tobar (1997).

obras sociales, directivos de empresas de medicina prepaga, responsables y plantel médico de la UOM - , y encuestas a 400 usuarios, mediante una muestra no probabilística por cuotas según sexo, edad, y nivel de calificación laboral en establecimientos médicos regionales seleccionados del Area Metropolitana).

Este artículo se compone de 4 secciones: la primera expone el marco conceptual, la segunda resume la presentación de resultados, la tercera sección plantea una discusión a la luz de los resultados y, finalmente, la última contiene algunas conclusiones y escenarios sobre el futuro del proceso de reforma.

\section{Marco conceptual}

Se encaró una triangulación en base a los siguientes enfoques: (a) la cuestión de la desregulación asimilada a una modalidad de privatización informal (Maingon, 1997); (b) el análisis del proceso de reforma desde la perspectiva de los actores, que aporta un enfoque que ensancha el espectro de análisis de las políticas públicas, ya que se prioriza como campo de estudio el proceso social tejido alrededor del surgimiento, tratamiento y resolución de cuestiones ante las que no sólo el Estado sino también otros actores adoptan políticas, lo cual supone relaciones bidireccionales de poder, influencia y negociación corporativa (Belmartino, 2000; Long \& Long, 1992; Oszlak \& O'Donnell, 1995); (c) la equidad en el acceso a los servicios de salud, teniendo en cuenta que la concepción de la reforma atenta contra el sentido de equidad - en el que todos deben tener una oportunidad justa para lograr plenamente su potencial en salud-, profundizando aún más las diferencias en la accesibilidad, en la calidad de la atención y en el tipo de información necesaria para una correcta decisión sobre un cambio de cobertura (Metzger, 1996; Whitehead, 1991). Ello re- 
quiere analizar la dimensión cultural que permea las representaciones sociales en la atención de la salud, considerando que las producciones socio-culturales, históricamente acumuladas en la sociedad, no pertenecen de igual manera a todos los individuos, sino a aquellos que detentan los medios y saberes para apropiárselos (Bourdieu, 1985).

\section{Presentación de los resultados}

Algunos datos sobre la fragmentación del sistema

La distribución según cantidad de afiliados de las obras sociales sindicales permite apreciar una alta concentración de titulares en pocas entidades, demostrando que, bajo el amparo de la organización por actividad productiva, los sindicatos conformaron numerosas instituciones con una reducida cantidad de beneficiarios. Muy pocas poseen capacidad instalada propia, son mayoritariamente instituciones financiadoras que contratan servicios con el sector privado y esporádicamente con los hospitales públicos. La relación entre el tamaño de las obras sociales y su ingreso promedio mensual per cápita, el ingreso promedio per cápita mensual (denominación utilizada por la Superintendencia de Servicios de Salud) se refiere a las cotizaciones que ingresan a las obras sociales por aportes y contribuciones correspondientes a los salarios más otros conceptos. Equivalencia en Argentina: \$1 =US\$1 (Superintendencia de Servicios de Salud, 1999) muestra diferencias significativas: mientras las obras sociales con un menor número de afiliados perciben, en promedio, un ingreso más elevado $(\$ 41,40)$, las de mayor concentración de titulares son más pobres $(\$ 27,80)$. Esta desigual distribución afecta además el nivel de las prestaciones médicas, ya que el número promedio de consultas disminuye a medida que decrece el nivel de ingreso medio de las entidades $(2,4$ consultas anuales en el tramo de menor ingreso y 5,7 consultas en el segmento de las obras sociales con mayor ingreso mensual - Superintendencia de Servicios de Salud, 1999).

Principales aspectos de la reconversión durante el período

- Los resultados de la libre elección de afiliados

La lentitud de la puesta en marcha de la libre elección se debió a la falta de un marco regula- torio global, a la fuerte oposición de los gremios a las medidas impuestas por decretos emanados desde el Poder Ejecutivo, y a la escasa organización de las obras sociales para enfrentar la apertura del sistema. Por ello se decidió que la competencia fuese, sólo en una primer etapa, entre obras sociales sindicales. Una segunda fase contemplaría la libre competencia entre obras sociales y empresas de medicina pre-paga. En enero de 1997 se estableció que Ios afiliados que opten por otra obra social se llevarán consigo el porcentaje de su salario, imponiendo como requisito adicional el percibir un ingreso superior a $\$ 240$ por mes. Durante un período de dos años (mayo/ 97 a mayo/99), 345.000 afiliados titulares (que con sus familiares ascienden a 862.500 personas) han decidido cambiar de obra social. Esta cantidad representa sólo el 7,5\% del total de afiliados titulares del sistema de obras sociales y el $8,2 \%$ del total de beneficiarios. Puede estimarse que, a fines del año 1999, la cifra total de pases haya trepado a 420.000 titulares. La distribución espacial de las opciones (según datos de la Superintendencia de Servicios de Salud,1999) exhibe una elevada concentración en el área Metropolitana de Buenos Aires.

¿Cómo se han distribuido los migrantes según el nivel de sus ingresos? La Tabla 2 muestra que dos tercios tienen un ingreso menor a $\$ 1.000$, sin embargo, al comparar la estructura de ingresos del total del sistema, este segmento ha optado por otra entidad en menor medida en relación a los que perciben ingresos mayores.

Al recalcular la cantidad de opciones según ingresos, puede desprenderse que, del total de afiliados que ganan menos de $\$ 1.000$, ha optado por otra obra social el 6\%, mientras que, del total de afiliados que ganan más de $\$ 1.000$, el porcentaje de opciones se incrementa al doble: el $12 \%$ de éstos ha decidido cambiarse. Aunque los pases aún representen una cifra poco significativa, un primer análisis de las características de los migrantes establece que los aspectos que también inciden en la probabilidad de cambio de obra social se relacionan a una menor edad (hasta 30 años de edad), a no tener grupo familiar a cargo, y a contar con una mayor información sobre las opciones (Montoya \& Colina,1999).

El balance de pérdidas y ganancias de las obras sociales muestra que las más perjudicadas en cuanto a cantidad de pases han sido las entidades grandes (más de 100.000 afiliados), en cambio las de menor número de afiliados se vieron beneficiadas con mayores migraciones. Pese a que estas últimas están en la mira de 
una reestructuración inmediata, fueron las que han ideado, como estrategia de supervivencia, mayores convenios no formales con pre-pagas (según fuentes de la Superintendencia de Servicios de Salud del año 2000, se efectuaron 53 convenios de transferencia de aportes). Se ha evidenciado, asimismo, una fuerte presión por parte de empresarios a cargo de sanatorios y bancos (fundamentalmente de capital extranjero) que obligaban al plantel de empleados a cambiar por obras sociales bajo convenio con empresas pre-pagas. Este escenario contribuyó a incrementar el descreme y un progresivo desfinanciamiento del sistema, especialmente entre las obras sociales más pobres, que sufrieron la pérdida de afiliados con elevados salarios.

\section{- Programa Médico O bligatorio}

El Programa Médico Obligatorio (PMO) conforma un paquete básico de prestaciones de asistencia en prevención, diagnóstico y tratamiento médico y odontológico obligatorio para las obras sociales y empresas de medicina pre-paga. Si bien su contenido es poco preciso, la cobertura contempla los programas generales de atención primaria a través de médicos de cabecera, atención secundaria y prestaciones complejas. El monto fijado para el PMO corresponde a la suma de $\$ 40$ mensuales por afiliado titular que incluye al grupo familiar independientemente de la cantidad de miembros. A través del FSR se estableció un mecanismo de compensación automática para aquellas entidades de menor ingreso, reintegrando la diferencia a la obra social, si el monto de la contribución de sus aportantes no alcanzaba a cubrir la suma estipulada. Este mecanismo optimizó la asignación destinada a paliar los ingresos de obras sociales pobres, aunque aún la cúpula sindical sigue conservando una significativa cuota para el manejo discrecional de dichos fondos.

- Programa de Reconversión de Obras Sociales

El FROS, subsidiado a través del Banco Mundial, tendía a mejorar su viabilidad técnica y financiera. Los objetivos se centraron en: (1) reconvertir la deuda existente a través de préstamos a largo plazo; (2) equilibrar la infraestructura de las obras sociales en cuanto a recursos humanos y físicos, a través de la reducción de personal y de la venta de establecimientos médicos subutilizados; y (3) implementar actividades de desarrollo institucional para mejorar los servicios de salud. Para acceder a dicho prés-

\begin{tabular}{|c|c|}
\hline Distribución de afiliado & gresos. \\
\hline & Nivel de ingresos (\%) \\
\hline \multicolumn{2}{|c|}{ Total de afiliados titulares al sistema } \\
\hline Menos de $\$ 1.000$ & 78 \\
\hline Más de $\$ 1.000$ & 22 \\
\hline Total & $100(4.593 .640)$ \\
\hline \multicolumn{2}{|l|}{ Total de migrantes } \\
\hline Menos de $\$ 1.000$ & 66 \\
\hline Más de $\$ 1.000$ & 34 \\
\hline Total & $100(345.000)$ \\
\hline
\end{tabular}

Fuente: Superintendencia de Servicios de Salud (1999).

tamo, se requería tener más de 10.000 beneficiarios, demostrar capacidad de repago y no poseer deudas en el momento de la solicitud. Sólo 30 entidades, de las 90 presentadas, alcanzaron definitivamente los criterios para ser incluidas en el préstamo. El total de beneficiarios de las 30 obras sociales (en su mayoría de más de 50.000 afiliados) cubre a casi 5 millones de beneficiarios y representa a más de la mitad de los beneficiarios del total del sistema.

La evaluación del FROS indica que algo más de la mitad del monto del préstamo fue destinado a saneamiento financiero (la mayoría de las entidades calificadas operaba con déficit y con un elevado nivel de endeudamiento con proveedores). Los resultados económico-financieros del Banco Mundial establecen que el préstamo ha logrado disminuir las deudas, aunque la mayoría aún mantiene déficit operativo. La reducción de personal y el saneamiento administrativo implicaron, además, reducir el promedio de costos administrativos. En relación a los cambios en el modelo del cuidado de la salud, se tendió a extender y mejorar algunas coberturas médicas para cumplir con el PMO; se intentó asimismo fortalecer la red de atención primaria de salud de las entidades grandes. Los cambios organizativos orientados fundamentalmente a lograr una mayor eficiencia mejoraron levemente los sistemas médicos de auditoría y la capacidad administrativa.

La postura de los actores involucrados

frente a la Reforma

A partir del análisis en profundidad de las entrevistas, se pueden detectar coincidencias y divergencias entre los actores. ¿Cuáles son las similitudes? Se centran en marcar la ineficien- 
cia del sistema de salud (alto costo y alta inequidad), así como la irreversibilidad de la reforma aplicada. Las discrepancias se refieren al papel del Estado y al manejo de las Obras Sociales: en un extremo, se halla la postura de los dirigentes sindicales a cargo de las obras sociales y de algunos representantes de los prestadores privados (sanatorios y clínicas que históricamente han estado relacionados con las obras sociales a través de prestaciones médicas), que sostienen la necesi dad de preservar al Estado en su responsabilidad sobre el sector. Aún reconociendo la inevitabilidad de su transformación, afirman descreer de las bondades y capacidades de autoregulación del libre mercado. Por ello plantean la necesidad de una mayor actividad reguladora, manteniendo el sistema de obras sociales, dado que constituye la base de una amplia solidaridad para los trabajadores. En el otro extremo, es unánime la posición proveniente de representantes del Gobierno saliente, de autoridades de los organismos internacionales y de los responsables de entidades de medicina pre-paga, de desregular el sector. La libre elección por parte del consumidor y el riesgo económico asumido por los prestadores son las herramientas válidas para lograr eficiencia y competitividad, rechazando modelos planificadores globales con injerencia del Estado.

No obstante, al interior de cada uno de estos grupos, hay diferencias de carácter político que hacen aún más complejo el proceso de negociación para una adecuada implementación técnica de la Reforma.

Para los sindicalistas, el proceso de reconversión significó una salida para paliar la crisis financiera, que fue encarada por algunos dirigentes de manera anticipada a los lineamientos estatales. Reconocen la necesidad de cambios, fusiones y reestructuración de sus entidades, pero no negocian el sentido de pertenencia a cada rama de actividad ni la estructura gremial. Consideran que el ingreso legal de las empresas de medicina pre-paga atenta seriamente contra la esencia del sistema solidario basado en la doctrina de la Seguridad Social. Pretenden apoyo financiero preferentemente de tipo estatal, pero no proveniente del Banco Mundial. Aquellos dirigentes que ingresaron en el FROS admiten cambios positivos en la organización de sus entidades, pero advierten que sólo les ayudó a prorrogar deuda, generando una situación financiera complicada a largo plazo.

Los representantes de clíni cas y sanatorios atienden por contratos al $60 \%$ de los afiliados de las obras sociales - desean preservar el ac- tual sistema porque la libre competencia podría, por un lado, quebrar el frágil concepto de solidaridad aún imperante y, por otro lado, se reducirían los contratos con las obras sociales. Dicen ser los más golpeados por la crisis de las obras sociales y consideran que son poco consultados en el diseño de reformas.

El sector privado admite que sus principales problemas pasan hoy por una pérdida de la rentabilidad financiera, por una mayor concentración de la oferta a raíz del ingreso de capitales extranjeros, por la reducción de la demanda potencial y por una mayor injerencia estatal. Si bien la regulación del sector aún hoy es mínima, la ley que reglamenta su funcionamiento sólo tiene media sanción en el Congreso a causa de pujas internas entre las diversas entidades que conforman el sector. Entre tanto, sigue rechazando categóricamente medidas aprobadas desde el Estado que afecten su funcionamiento (aplicación del Impuesto al Valor Agregado y cumplimiento del PMO para prepagas). Cree que los sindicalistas utilizan las obras social es como mecanismo para obtener poder político y centra sus críticas en la ausencia de eficiencia por la falta de competencia en el sistema. Aunque el principal reclamo del sector sea el ingreso formal bajo una libre competencia, el actual esquema de contratos con cerca de 60 obras sociales le parece por ahora conveniente, dado que la apertura legal implicaría una necesaria reformulación de su organización y la adaptación de sus planes para aceptar a usuarios de bajos ingresos.

La postura de los diferentes actores muestra dificultades para articular consenso a la hora de pensar posibles estrategias integradoras, en un área fuertemente politizada, con inexistente capacidad de arbitraje en el seno del Estado, y en la que la población beneficiaria no es tenida en cuenta en su percepción de necesidades, teniendo poca capacidad de traducir sus demandas en la conformación de la agenda política del gobierno (Belmartino, 2000).

El nivel micro: la Obra Social del sindicato de la Unión Obrera Metalúrgica

El sindicato metalúrgico - creado bajo la primera Presidencia del Gral. Perón en 1940 y en pleno crecimiento del sector industrial argentino - contaba en 1970 con 550.000 afiliados titulares y más de un millón de beneficiarios. Tanto los salarios como la cantidad de afiliados del sindicato caen abruptamente desde 1970 hasta la actualidad (su población asciende hoy a 163.000 afiliados titulares y 500.000 beneficiarios). La apertura de la economía y las polí- 
ticas de convertibilidad implementadas a comienzos de los 90 implicaron la quiebra de varias fábricas metalúrgicas de pequeña y mediana envergadura y la privatización de otras de gran tamaño. Es la entidad que lidera las mayores pérdidas de afiliados. Los motivos son diversos: pases hacia el gremio metalmecánico como producto de acuerdos entre empresarios y sindicalistas para negociar mejores convenios colectivos, divergencias ideológicas internas, presiones de empresarios del sector hacia sus empleados para que opten por entidades de medicina pre-paga, y una disminución progresiva de la calidad de atención de sus prestaciones médicas a raíz de su delicada situación financiera. Es una de las obras sociales con mayor infraestructura propia en los grandes centros urbanos. Su reconversión, encarada sin una suficiente planificación previa, se implementa para paliar una grave crisis que tiene sus orígenes en fuertes deudas contraídas - y aún no condonadas - por la prolongada intervención del gremio durante la dictadura militar.

Una tabla de salvación fue la pretensión de ingresar al FROS, estrategia ideada sólo para evitar el pedido de convocatoria de acreedores, dado que los dirigentes del Secretariado Nacional rechazaban enérgicamente cualquier proyecto que implicara disminuir infraestructura propia e incentivar mayor subcontratación con el sector privado. De todas maneras, serios conflictos de intereses entre autoridades del gobierno saliente (pujas entre la Jefatura de Gabinete y el Ministerio de Economía), que requerían condonar las deudas de la UOM para acceder al préstamo del Banco, han impedido su efectiva incorporación al Programa de Reconversión. Dicha negativa profundizó un serio ajuste, basado en: (a) despidos del plantel médico y recontratación por modalidad de honorarios; (b) pedido ante el Ministerio de Trabajo de reducción de sueldos de colaboradores y directivos del sindicato; (c) gerenciamiento privado de la regional de zona norte del Area Metropolitana; (d) delegación de fondos para el manejo descentralizado de los centros médicos propios para la compra de insumos, servicios de mantenimiento y honorarios ó sueldos, sin la suficiente capacitación a directores médicos y administrativos de los Centros Hospitalarios. Dicha crisis provocó serios problemas en el adecuado funcionamiento de los Centros (retrasos en el otorgamiento de turnos para consultas, prácticas especializadas e intervenciones, corte en el suministro de insumos), debiendo acudir - como única vía - al pedido de convocatoria a fines de noviembre de 1999. Las pujas internas y un manejo sumamente cen- tralizado del gremio afectan las decisiones sobre su futuro.

La visión de los usuarios de

Ia Unión Obrera Metalúrgica

La indagación a usuarios de la obra social se basó en conocer opiniones sobre uso de prestaciones, evaluación de la calidad de atención médica, información sobre la libre elección de entidades y predisposición al cambio de obra social. El perfil de la muestra relevada durante el último trimestre del año 1999 tiene un promedio de edad de 35 años, bajos niveles de educación y de ingreso promedio mensual, elevada antigüedad de afiliación y alta cobertura exclusiva de obra social.

Los principales resultados señalan que la cercanía al domicilio es la razón primordial por la que los usuarios que se atienden en los centros regionales del Gran Buenos Aires. Los que concurren al Policlínico Central (ubicado en Capital Federal) optan por este centro por tener una oferta de servicios más completa, aunque les demande un mayor tiempo de viaje. Si bien 7 de cada 10 entrevistados con prescripción médica en sus consultas señalan facilidad en la obtención de los medicamentos, aquellos que encuentran dificultades son predominantemente las mujeres, usuarios de más de 60 años, los de menor nivel de educación y con bajos ingresos mensuales.

La evaluación general para todos los aspectos relacionados con la atención médica es positiva, pero pueden detectarse diferencias en cada una de las dimensiones según los perfiles socio-demográficos de los usuarios. La valoración tiende a ser más elevada cuando se califica al personal médico (calidad profesional de los médicos, atención de los médicos y atención de las enfermeras). La calificación decrece algo al evaluar la atención del personal administrativo y la tecnología de los centros de atención y es menor cuando recae en la atención: tiempos de espera para la obtención de turnos, cita con el médico y realización de estudios. Los entrevistados de mayor edad, menor nivel de educación y bajos ingresos mensuales se inclinan en mayor medida a calificar mejor todos los aspectos, en cambio, los más jóvenes, de mayor nivel de instrucción e ingresos mensuales son más críticos a la hora de evaluar la atención. El promedio de calificación general dela obra social se construyó solicitando a los entrevistados que calificaran a la entidad globalmente en base a una escala que abarca desde un límite inferior de un punto (baja calificación) hasta 10 puntos (alta calificación) y muestra un 
elevado índice de satisfacción (7,27 puntos). Nuevamente se observa que, a menor educación y menor ingreso mensual, crece la valoración global. Una amplia mayoría de los usuarios (83\%) está informada sobre la posibilidad de cambio de Obra Social. Sin embargo, sólo un tercio estaría dispuesto a optar por otra obra social, y más de la mitad (55\%) desean permanecer en la UOM. ¿Cuál es la franja más crítica y mayor predispuesta al cambio? Son mayormente hombres, de hasta 29 años de edad, con mayor nivel educativo y mayores niveles de ingreso. ¿Y quiénes se quedarían? Son preferentemente mujeres, mayores de 45 años, con calificaciones hacia la obra social superiores al promedio, con bajos niveles de instrucción y de ingreso mensual. Los que piensan quedarse en la obra social destacan como principales razones la conformidad, la costumbre y el sentido de pertenencia; también se mencionan la satisfacción con la atención médica y la creencia que la UOM otorga mayores beneficios en comparación con otras obras sociales; desconocen servicios ofrecidos por otras entidades y, si bien perciben algunos problemas en la atención, creen que éstos son coyunturales, anhelando un mejor funcionamiento. El segmento de futuros migrantes considera, en cambio, que otras entidades pueden otorgar mayores beneficios que los que presta la UOM, no percibe soluciones inmediatas a la crisis y consideran que los actuales dirigentes sindicales son los únicos responsables del estado actual de la obra social.

\section{Discusión de los resultados}

El proceso de reforma de la seguridad social es el reflejo de una profunda transformación económica que revela en su interior una lógica altamente fragmentada, con presencia de actores corporativos que imponen sus propios intereses, y con manifiestas ausencias de resortes institucionales parlamentarios, ya que la mayoría de los ejes fueron el resultado de decretos emanados por el Poder Ejecutivo. Si bien se puso énfasis en mejorar la eficacia y eficiencia de las obras sociales, no se planteando explícitamente mejorar la equidad, algunos de sus ejes podrían haber sido favorecedores de una mayor equidad, como por ejemplo la homogeneización de los servicios en un programa básico de prestaciones, la posibilidad de una libre elección de entidades y una mejor adjudicación de los subsidios correspondientes al Fondo Solidario de Redistribución. Sin embargo, el análisis de los cambios señala que: a) la apertura limitada de la libre elección (que incluyó el ingreso no formal de las entidades de medicina pre-paga, avalado por algunos dirigentes sindicales) no provocó una masiva migración de afiliados, pero se vislumbra ya un cierto nivel de descreme (selección por riesgo) que puede profundizar aún más una estructura bastante inequitativa y fragmentada.

b) el Programa Médico Obligatorio no logró una adecuada uniformidad en su aplicación, ya que está sujeto a una estratificada recaudación de las entidades y a una desigual distribución de su monto entre usuarios con diferentes grupos familiares. El escaso control de su homogeneidad cuantitativa generará estrategias de selección adversas por la posible proliferación de planes diferenciales, que tenderán a devaluar cualitativamente al conjunto básico de beneficios para captar aportes hacia planes más caros (Alonso, 1999).

c) El primer conjunto de obras sociales que reciben asistencia del Fondo de Reconversión del Banco Mundial logró mejorar relativamente la eficiencia interna de sus entidades, en comparación con las no reconvertidas, especialmente en la optimización de sus indicadores económico-financieros. Pese a ello, el costo final de dicho Programa implicará para las entidades una generación de deuda a largo plazo con el Banco que, en un escenario de contracción económica, no resultará fácil de cumplimentar.

d) El estudio de caso sobre la UOM muestra, a nivel micro, las falencias de un sistema de seguridad social creado en otro contexto económico y político, que presenta dificultades para adaptarse a las nuevas normas impuestas por la desregulación. Las serias restricciones en la oferta de los servicios médicos, producto de su profunda crisis financiera, perjudican a Ios usuarios como sujetos activos del proceso de reforma. La tendencia muestra una progresiva limitación en el acceso a los servicios de salud para un segmento conformado por usuarios de mayor edad, menor instrucción y menor ingreso mensual. Esta franja es la que mejor evalúa a su obra social y más privilegia el sentido de hábito y pertenencia. En ese sentido puede rescatarse a Bourdieu (1985), cuando plantea que la adquisición de saberes culturales incide en una mejor discriminación de la calidad de los servicios. Si la UOM lograra salir de su aguda crisis financiera e intentara reposicionarse en un contexto más competitivo, estaría en condiciones de retener a este segmento - minoritario - de futuros migrantes. En caso contrario, seguiría siendo la obra social que lidera las mayores pérdidas de afiliados. Parece 
que la única alternativa que tiene para subsistir, aprovechando la fortaleza de su red de servicios, pasa por la fusión, asociación o integración con otras entidades. El interrogante es hasta qué punto dicha alternativa resulta viable mientras no modifique su cultura organizacional, sumamente verticalista y tradicional, que ya no logra imponerse debido al debilitamiento de sus influencias políticas y de su escasa capacidad de presión y negociación en un contexto que le es crecientemente adverso.

\section{Conclusiones y recomendaciones: el futuro de la reforma}

El rumbo de la reconversión, a partir de la asunción del gobierno del partido de la Alianza, que dirige el Dr. de la Rúa, parece consolidarse y profundizarse. Se impondrá la fusión de entidades para aquellas obras sociales con serios problemas de liquidez, intentando impulsar la inviabilidad de un sistema con 280 entidades. También parece activarse el ingreso legal de las empresas de medicina pre-paga, en franca competencia con las pocas obras sociales que finalmente sobrevivan. Para ello se preven una mejor asignación del PMO por afiliado y la ampliación del monto del Fondo Solidario de Redistribución para paliar la desfinanciación de las obras sociales con mayores migraciones. Para los actores, el escenario futuro es incierto y más bien adverso. El sector privado, interesado en entrar en el sistema, no acuerda con el nuevo monto del PMO y deberá disminuir sus costos a expensas del usuario, que terminará pagando adicionales para acceder a una cobertura integral. Los sindicalistas deberán aceptar la fusión de entidades, exigirán mayores montos para cubrir el PMO y seguirán rechazando, en el plano discursivo, el ingreso de las pre-pagas a fin de preservar su identidad. Las nuevas autoridades tenderán a optar, en una primera etapa, por estrategias de confrontación con los sindicatos, lo cual permitirá cumplir con las metas impuestas por el Banco Mundial (ingreso formal de las pre-pagas al sistema). Aunque existan algunas propuestas para evitar la desfinanciación del sector, y atenuar el riesgo del descreme ante la libre competencia con el sector privado, es poco probable que disminuya a corto plazo la inequidad del sistema. Éste continuará sumamente polarizado: en un extremo se ubicarán los beneficiarios con mayor capacidad de pago que tendrán acceso a ofertas más prestigiosas en entidades privadas y, en el outro, quedarán los afiliados de menores ingresos y menor información sobre las opciones (Whithead, 1991), accediendo a limitados servicios de salud, ofrecidos por obras sociales en vías de fusión y reorganización, cuyos dirigentes estarán más preocupados en adecuarse a la nueva lógica y en resolver sus problemas financieros que en esmerarse por brindar una adecuada calidad de atención médica en un contexto de baja regulación estatal y escasa articulación sectorial.

\section{Agradecimientos}

Proyecto financiado por la Red de Investigación en Sistemas y Servicios de Salud del Cono Sur y por la Secretaría de Ciencia y Técnica de la Universidad de Buenos Aires (UBA). Sede: Instituto de Investigaciones Gino Germani, Facultad de Ciencias Sociales UBA, Argentina. Coordinadora: Lic. Liliana Findling (socióloga, UBA); Investigadores: Lic. María Arruñada (socióloga, UBA) y Dr. Ezequiel Klimovsky (médico especialista, UBA); Asistente de investigación: Lic. Josefina Rossi (politóloga, Universidad Nacional de La Plata). Agradecemos especialmente el asesoramiento académico, los pertinentes comentarios y el constante apoyo en la elaboración del proyecto de la Dra. Celia Almeida (coordinadora general de la Red de Investigación en Sistemas y Servicios de Salud), del Dr. Mario Bronfman (asesor externo del proyecto) y de la Lic. Alicia Stolkiner (coordinadora de la Red en Argentina). 


\section{Referencias}

ALONSO, G., 1999. La regulación del sistema de salud en la Argentina. Dimensiones conceptuales para el estudio de la capacidad institucional. In: Serie III. Políticas Públicas. Documento № 41. (Dirección Nacional de Estudios y Documentación \& Dirección de Estudios e Investigaciones, org.), pp. 9-36, Buenos Aires: Instituto Nacional de la Administración Pública.

BELMARTINO, S., 2000. Nuevas Reglas de Juego para la Atención Médica en la Argentina. Buenos Aires: Lugar Editorial.

BOURDIEU, P., 1985. ¿QuéSignifica Hablar? Madrid: Akal Universitaria.

CETRANGOLO, O. \& DEVOTO, F. F., 1998. Reformas en la Política deSalud en Argentina Durantelos Años 90 con Especial Referencia a la Equidad. Serie de Estudios 7. Buenos Aires: Centro de Estudios para el Cambio Estructural.

GONZALEZ-GARCIA, G. \&TOBAR, F., 1997. Más Salud por el Mismo Dinero. Buenos Aires: Ediciones Isalud.

LONG, N. \& LONG, A., 1992. Battlefields of Knowledge. London: Routledge.

MAINGON, T., 1997. Proceso de privatización en los servicios de salud en América Latina y el Caribe: Estudio de casos. Población y cambio social. Revista Latinoamericana de Población, 1:1-29.
METZGER, X., 1996. Conceptualización eIndicadores para el Término "Equidad" y su Aplicación en el Campo de la Salud. Washington, DC: Health Situation Analysis Program, Panamerican Health Organization. (mimeo.)

MONTOYA, S. \& COLINA, J., 1999. La Reforma delas Obras Sociales en Ia Argentina: Avances y Desafíos Pendientes. Córdoba: Instituto de Estudios sobre la Realidad Argentina y Latinoamericana, Fundación Mediterránea Córdoba. (mimeo.)

OSZLAK, O. \& O'DONNELL, G., 1995. Estado y políticas estatales en América Latina: Hacia una estrategia de investigación, Universidad Nacional de Quilmes, Bernal. Redes, 2:97-128.

SUPERINTENDENCIA DE SERVICIOS DE SALUD, 1999. Obras Sociales. Información General del Sistema. Buenos Aires: Acción Social de la Nación, Ministerio de Salud.

WHITEHEAD, M., 1991. Los Conceptos y Principios de la Equidad en Salud. Serie Reprints 9. Washington, DC: Programa de Desarrollo de Políticas de Salud, Centro de Documentación e Información, Organización Panamericana de la Salud.

Recibido el 8 de febrero de 2001

Versión final presentada el 10 de julio de 2001

Aprobado el 3 de octubre de 2001 